Volume 11(3) (2014), 285-298

Copyright (c) Equinox Publishing Ltd

Sheffield

http://equinoxpub.com

DOI: 10.1558 /cam.v11i3.24806

\title{
Does gender matter in doctor-patient communication during standard gynaecological consultations? An analysis using mixed methods
}

\author{
MARIA ANGELA MAZZI ${ }^{1}$, MICHELA RIMONDINI ${ }^{1}$, MYRIAM DEVEUGELE ${ }^{2}$, CHRISTA \\ ZIMMERMANN $^{1}$, GIUSEPPE DELEDDA ${ }^{3}$ AND JOZIEN BENSING ${ }^{4}$
}

(1) University of Verona, Italy (2) University of Ghent, Belgium (3) Ospedale Sacro Cuore Don Calabria, Italy

(4) NIVEL, Utrecht University, The Netherlands

\section{Abstract}

This paper assesses whether gender plays a role when male and female participants discuss the quality of doctor-patient communication in gynaecological consultations. A European multi-centre study was conducted comprising 259 participants in 35 genderand country-specific focus groups. In all focus groups, a set of four videotaped Objective Structured Clinical Examination (OSCE) consultations was used as a prompt for discussion. The doctors' ability in communication was assessed by participants' ratings and by a quantified content analysis of their comments, using a mixed-method approach. Gender analysis was performed applying a set of generalized linear regression models.

The findings indicated that gender differences were smaller than expected. The individual ratings of the overall quality of communication were similar for male and female participants, and there were hardly any differences in the content of the discussions. The only two exceptions were that female doctors were criticized more than male doctors when they made impersonal comments and that female participants were more outspoken than men, positively and negatively. The prevalence of gender similarities suggests that doctors' empathy, support, understanding and pleasantness are highly appreciated by both male and female participants and appear to transcend gender differences.

Keywords: doctor-patient communication; focus group; gender; mixed methods; quality ratings

\section{Introduction}

In the literature on doctor-patient communication, gender plays a modest but consistent role. Empirical studies have paid attention to gender role performance, role expectations, preferences and the experiences of patients and doctors (Bensing et al. 1993; West 1993; Kerssens et al. 1997; Roter et al. 2002; Arber et al. 2006; Thornton et al. 2011). Different methodologies have been applied, according to the outcome measure or the target gender (whether doctor or patient, or both) (Dielissen et al. 2011), such as interaction analysis systems or expert observer ratings (Blanch-Hartigan et al. 2010). One recurrent finding regarding doctors' communication style, for example, is that female doctors adopt behaviour that is more 'patient-centered' (Roter and Hall 2004; Bertakis et al. 2009; Jefferson et al. 2013), suggesting a gender role performance corresponding to what patients would expect from a female doctor. Also, female patients have been found to talk more about their emotions than male patients (Hall and Roter 1995). Surprisingly, however, studies of patients with gynaecological complaints have shown that the gender of the doctor does not appear to have an influence upon such patient affective expressions (Hall and Roter 2002).

Qualitative and quantitative measures based on in-depth interviews with patients and their self-rated scales are used when exploring a range of issues in the field. These include: the patient's 
expectations of the doctor's gender role; the patient's general preference with regard to the gender of the doctor; the patient's personal experiences with male or female doctors; and the patient's evaluation of doctors' communication skills when observing videotaped consultations (Dielissen et al. 2011). For example, analogue patients who observed videotaped Objective Structured Clinical Examinations (OSCE) perceived patient-centred male medical students to be more competent than female ones (BlanchHartigan et al. 2010).

Recent research has focused on the effects of doctor-patient dyads of the same gender during medical consultations (Sandhu et al. 2009; Schieber et al. 2014). It was found that gender concordant dyads result in greater patient-oriented interactions and in greater patient trust and enablement (Brink-Muinen et al. 2002; Bertakis et al. 2009; Banerjee and Sanyal 2012). In fact, it has been hypothesized that the patient's satisfaction with their consultation might improve when a doctor adopts an approach towards communication which fits the patient's gender role expectations. Gender thus may have a moderating effect on the relationship between the doctor's approach towards communication and the patient's satisfaction (Hall et al. 1994; Schmid Mast et al. 2008).

Experts in medical education have thus proposed specific teaching programmes to improve attitudes and skills around gender issues in medical practice (Dielissen et al. 2009; Lagro-Janssen et al. 2010; Dielissen et al. 2012), although a Swedish research group found that among leading experts, males tend to maintain that gender-related issues in medical practice are overemphasized or 'important [...] but of low status' (Risberg et al. 2011). While experts disagree and there is an ongoing debate in the literature about the nature, size and relevance of gender issues in medical communication, it is reasonable to let patients themselves determine whether or not 'doctor gender' is an important issue in the medical consultation room. The findings of such a study might be of relevance for healthcare and promotion planning (Wolosin and Gesell 2006) as well as teaching purposes (Risberg et al. 2003).
The present study endorses this view, and uses data from the large dataset of an international multicentre study, GULiVer, which addresses patients' views on good doctor-patient communication. GULiVer documented views both individually, through rating scales, and collectively, through focus group discussions (Mazzi et al. 2015). The GULiVer study design made use of male-only and female-only panels, and both male and female doctors, and this allows researchers to explore whether or not the communication ability of male and female doctors is rated differently by males and females.

Three research questions were investigated:

1. Are there gender differences in the quality ratings of doctors' communication by female and male participants?

2. Are there any differences in the kind of topics that are discussed in male and female focus groups with regard to doctors' ability to communicate?

3. Are there differences between male and female participants in what is liked or not liked about the way the doctors communicate?

\section{Method}

\subsection{Design}

A set of 35 focus groups was conducted in an international study which draws its name, GULiVer, from the four centres involved: Ghent University (Belgium), Utrecht University (the Netherlands), Liverpool University (UK) and the University of Verona (Italy). Three centres organized nine focus group meetings each, while Belgium had eight meetings. The same procedures were followed in each focus group, according to a detailed protocol (Moretti et al. 2012).

In order to produce the same prompt for all focus groups, we aimed to select videotaped medical consultations fulfilling three criteria: (1) standardization of medical consultation; (2) variety in the quality of doctor communication; and (3) a sensitive gender-related medical problem (Christen et al. 2008). Following these criteria, two sets of four videotaped Objective 
Structured Clinical Examination (OSCE) consultations, provided by the Liverpool Medical School and designed to test the quality of students' interviewing skills during their final (fourth year) examinations, were selected to be used as a prompt for the focus group discussions. Students, referred to as 'Doctor', had to gather facts about a simulated patient's condition. The consultations (detailed in Table 1) referred to two different scenarios, both about gynaecological problems associated with high levels of emotional distress. Scenario 1 concerned vaginal discharge caused by a Sexually Transmitted Disease (STD); Scenario 2 concerned Period Pain (PP) resulting in absenteeism from work. For each scenario four videotaped doctors were selected with different levels of communication performance. These were evaluated by the examiners and the simulated patient involved according to the Liverpool Communication Skills Assessment Scale (LCSAS) and the Global Simulated Patient Rating Scale (GSPRS) respectively (Humphris and Kaney 2001). Half of the panels were shown the four videos relating to Scenario 1, with the rest shown the four videos for Scenario 2.

Table 1. Characteristics of the videotaped consultations

\begin{tabular}{l|lcc}
\hline & \multicolumn{3}{|l}{ video characteristics } \\
\hline \multirow{3}{*}{ Scenario } & \multicolumn{3}{l}{} \\
\hline \multirow{3}{*}{ Period pain } & Doctor gender & LCSAS $^{\mathrm{a}}$ & GSPRS $^{\mathrm{b}}$ \\
& male & 39 & 10 \\
& male & 28 & 10 \\
& male & 37 & 5 \\
& female & 28 & 6 \\
\hline \multirow{3}{*}{ texually } & female & 39 & 9 \\
disease & female & 25 & 9 \\
& female & 37 & 6 \\
& male & 28 & 6 \\
\hline
\end{tabular}

a LCSAS: score:0-39 (low $<29$ - high $>36)$

${ }^{\mathrm{b}}$ GSPRS score: $1-10($ low $\leq 6-\operatorname{high} \geq 8)$

The type of medical problem presented in the videotaped consultations (sensitive gynaecological problems) influenced the composition of the focus groups in our study. The decision to use single-gender focus groups of men and women followed Morgan (1996), who advises on this procedure when gender issues are the focus of study. People are likely to feel more comfortable talking openly and honestly about intimate, taboo or otherwise sensitive topics with others of the same gender (Betts et al. 2008). Homogeneous gender groups also allow topics to be explored which are seen as appropriate by some but not all groups - what may be of relevance or concern to female participants may not necessarily be so to male participants (Betts et al. 2008). A final reason to choose same-gender focus groups is that while mixed groups seem to be more effective in problem-solution tasks, they tend more towards conformity. It seems that homogeneous groups are more suitable when the aim of the study is to find a diversity of opinions, ideas and views (Stewart and Shamdasasi 2014), which was primarily the aim of our study.

In line with this aim, we decided to choose the mixed-method approach for the analysis of the data. Compared to more traditional qualitative methods, this may have the disadvantage that nuances or subtleties of the discussions might get lost, but it has two important advantages: first, by counting the number of times certain topics are discussed, it is possible to get an idea of the importance of these topics for the participants; and second, quantification of the data enables comparison between groups (in this case female vs male participants) and the control of background variables (socio-demographic characteristics) by the use of statistical techniques.

\subsection{Participants}

The 259 participants (123 men and 136 women) were recruited from the general population. Recruitment took place via adverts in free local newspapers and by word-of-mouth. To be included, participants had to be over 18 years old and to have visited their GP at least once during the last year. To avoid negative biases, having filed a medical-related complaint or lawsuit over the past few years was used as an exclusion criterion The sample was stratified by age as well as gender, with each focus group consisting of six to eight participants covering three different age groups: 18-30, 31-49 and 50+. There were 64 participants from the Netherlands (NL), 72 from Italy (IT), 75 from the UK and 48 from Belgium (BE). 


\subsection{Procedure}

The participants attended a one-day meeting, where they watched the four videotaped consultations and carried out various tasks (Moretti et al. 2012). The videos were either dubbed (IT) or subtitled (NL and BE) to conform to the accepted practice of displaying English-language audio on television in the various countries. Written transcripts of the consultations were also provided in the language of the participants. Two tasks were the subjects of the present study. After watching each video, participants individually rated the overall communication ability of the doctor on a Likert scale (1-10). In the subsequent focus group they discussed their views on the four doctors observed, shared their views regarding the doctors' approach to communication, and provided underlying reasons for their opinions. Each discussion was audiotaped, transcribed and, apart from the UK material, translated into English. Care was taken to maintain the link between each contributing statement and its author.

\subsection{Content analysis}

Content analysis was used to analyse the data. This is a rigorous technique based on clear definitions (coding scheme), reproducibility of the assignment of text to values and reliability of the coding (which is measured using inter-coder agreement statistics) (Pluye and Nha Hong 2014). It is used 'for simplifying phenomena' because it can reduce a large amount of textual data into a small number of variables that can be analysed by using a statistical approach (Hsieh and Shannon 2005; Bernard and Ray 2010).

Researchers from each centre applied an inductive content analysis of a selected set of focus group discussions, in order to derive a common coding framework ('GULiVer coding system' - see Appendix) with which to classify each participant's statement, following a rigorous coding protocol (Moretti et al. 2011). Participants' speech turns were split into more than one statement (hereafter called units of analysis) when consisting of different comments on doctors' performance. The unit was classified into categorical variables, expressing both the topic of participants' comments and their value (coded as 'positive', 'negative' or 'neutral').

\subsection{Data analysis}

Table 2 shows the target and independent variables for each of the three research questions and the statistical approach used. A set of generalized linear regression models explored the presence of gender differences which were due to doctors, participants - that is to say the main effects - and their interaction (dyad effect). An appropriate linked function was chosen for each type of dependent variable. To take into account the nested structure of the study design - repeated measures within participants or within focus groups - the 'cluster' option was adopted in the Stata commands. GSPRS and LCSAS, together with country and scenario variables, were entered into the regression model for the first research question in order to adjust for design effects. The analyses were performed using Stata 11.2 (Stata Statistical Software 2011).

\section{Results}

\subsection{Are there gender differences in the quality assessment of doctors' communication by female and male participants?}

The global quality rating of male and female doctors' ability to communicate did not differ between male and female participants. The mean rating of female participants was 6.8 (sd 1.9; range 6.4-7.5) for male doctors and 6.6 (sd 1.7; range 6.3-6.9) for female doctors; that of male participants 6.9 (sd 1.6; range 6.6-7.3) and 6.7 (sd 1.8; range 6.6-6.9) respectively. These results were confirmed by the linear regression: no significant main effects (relating to the doctor and participant gender), nor interaction effect were identified (see Table 3).

\subsection{Are there any differences in the kind of topics that are discussed in male and female focus groups with regard to doctors' ability to communicate?}

Overall, the number of statements made in the focus group discussions about male and female 


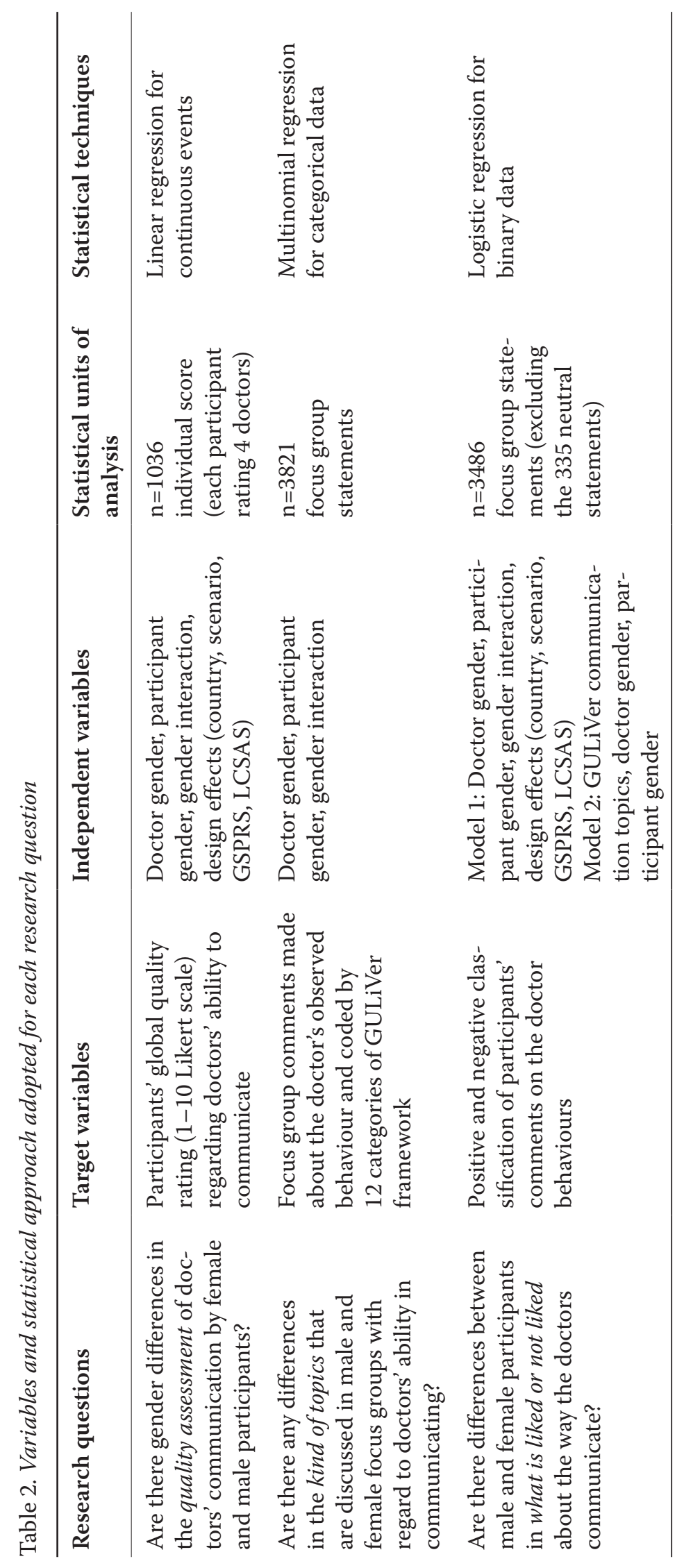

\section{eevunoxonlıne}


290 Maria Angela Mazzi et al.

Table 3. The effect of gender and design features on participants' ratings of doctors' communication quality evidenced by linear and logistic models

\begin{tabular}{|c|c|c|c|c|}
\hline \multirow[b]{2}{*}{ Variables } & \multicolumn{2}{|c|}{$\begin{array}{l}\text { Linear regression on } \\
\text { 10-point Likert scale }\end{array}$} & \multicolumn{2}{|c|}{$\begin{array}{l}\text { Logit regression on } \\
\text { pos/neg statements }\end{array}$} \\
\hline & $\mathrm{b}$ & $95 \%$ C I & OR & $95 \%$ C I \\
\hline \multicolumn{5}{|l|}{ Participant characteristics } \\
\hline Doctor gender (female vs male) & -0.07 & $-0.38-0.25$ & 0.97 & $0.69-1.38$ \\
\hline Participant gender (female vs male) & -0.07 & $-0.39-0.24$ & 0.70 & $0.51-0.96$ \\
\hline Gender interaction & -0.08 & $-0.49-0.32$ & 1.25 & $0.76-2.03$ \\
\hline \multicolumn{5}{|l|}{ Design effect } \\
\hline $\begin{array}{l}\text { Country: IT vs NL } \\
\text { UK vs NL } \\
\text { BE vs NL }\end{array}$ & $\begin{array}{l}-0.13 \\
-0.20 \\
-0.11\end{array}$ & $\begin{array}{l}-0.60-0.34 \\
-0.59-0.20 \\
-0.66-0.44\end{array}$ & $\begin{array}{l}1.18 \\
1.08 \\
1.07\end{array}$ & $\begin{array}{l}0.89-1.57 \\
0.83-1.42 \\
0.80-1.43\end{array}$ \\
\hline Scenario: PP vs STD & -0.07 & $-0.46-0.32$ & 0.87 & $0.69-1.09$ \\
\hline GSPRS & 0.08 & $0.02-0.13$ & 1.15 & $1.07-1.24$ \\
\hline LCSAS & 0.03 & $0.01-0.04$ & 1.03 & $1.00-1.05$ \\
\hline constant & 5.63 & $4.88-6.38$ & & \\
\hline
\end{tabular}

C I=Confidence Interval

Significant coefficients in bold

doctors was fairly similar (1,915 and 1,906 respectively), while participants made more comments on behaviours of doctors of the opposite gender $\left(\mathrm{X}^{2}(1)=5.04, \mathrm{p}=0.03\right)$.

Overall, there were more similarities than differences between the gender groups, and when differences reached significance, they were usually rather small. The most important differences are presented below.

Doctor's gender: In Table 4, the multinomial regression findings show that female doctors attracted more comments on their non-verbal behaviour than male doctors $(11 \%$ vs $7 \%$; $\mathrm{RRR}=1.70$ - 'Because despite the fact she had eye contact, it was minimal. It really was minimal.' [man, NL]) and their being judgmental or too personal in their remarks ( $5 \%$ vs $2 \%$; $R R R=3.41$ - 'This digression was not very pleasant, I did not like it, seemed a bit malicious. Sure she had fun but, not [...]? [woman, IT]). Male doctors evoked more comments on how they opened or closed the interview ( $5 \%$ vs $2 \%$; RRR $=0.20$ - 'But right at the start all he says his name and then says "I have been asked to speak to you today to see why you have come in today, is that alright with you". [man, UK]). This was discussed in particular by female participants (interaction effect $R R R=2.96$ ). Male doctors also evoked more comments about how they handled time issues ('He went through the whole thing fast. Too fast.' [man, NL]). This was discussed in particular by male participants (interaction effect $R R R=0.22$ ). Interestingly, male doctors also induced more discussion among both male and female participants about their affective-oriented communication in terms of being inviting ( $4 \%$ vs $2 \%$; $R R R=0.39-$ 'He also asked "if there is anything you don't understand, please indicate." That was a very strong point. [...] That was good about him.' [man, NL]), facilitating (2\% vs 1\%; RRR=0.31 - 'I liked very much when he asked her if there was another question she would like to ask, to help her to talk.' [woman, IT]), or listening ( $2 \%$ vs $1 \%$; $R R R=0.39$ - 'Some of them really listened to the patient and what she had to say' [man, UK]).

Participant's gender: Female participants commented more frequently that doctors' behaviour was perceived as self-confident ( $6.5 \%$ vs $4.3 \%$; $R R R=2.20$ - 'Yes, much more self-confidence than that female doctor. [...] Well yes, he knew how to go along [...].' [woman, BE]). Male participants discussed more often how doctors were 
providing solutions ( $3.6 \%$ vs $2.4 \%$; RRR $=0.42$ - 'I appreciated him. [...] He promised a solution of the problem, two or three times. [man, IT]) and showed empathy (3.3\% vs $1.4 \%$; RRR $=0.23-$ 'That is also how she asked questions, she could empathize very well.' [man, NL]). With regard to empathy, participants talked most about empathy issues related to the doctor of their own gender (interaction effect RRR=3.29).

\subsection{Are there differences between male and female participants in what is liked or not liked about the way the doctors communicate?}

Inspection of the positive and negative values attached to the statements showed that the female participants were less positive than male participants about both female and male doctors ( $46 \%$ vs $52 \%$; $\chi^{2}(1)=12.0 \mathrm{p}<0.01$ ). This participant gender effect was confirmed by the logistic regression adjusted for design effect $(\mathrm{OR}=0.70)$, with no doctor gender or gender interaction effect, as shown in Table 3.

Table 5 shows the findings of a parsimonious model, which explored the main effects of communication topics, the doctor's and the participant's gender, the two-way interactions between topics and the doctor's and the participant's gender, respectively. Independent of the doctor's or the participant's gender, the most appreciated behaviours overall were: Pleasant attitude $(72 \%$; OR $=4.53-$ - ... and I thought I could tell her anything. She was very, very relaxed and friendly'. [woman, UK]); Reassurance (67\%; $\mathrm{OR}=2.25$ - 'I found that he could have reassured her more.' [woman, NL); and Empathy (75\%; $\mathrm{OR}=2.52$ ). Other factors were more likely to be discussed in negative terms (range from 69-89\%; OR from 0.20-0.30). Among these were Speaking peculiarities ('I didn't think it was bad, but all those double questions and answers, no, [...] uh, I wouldn't send my daughter or wife to him. [man, NL]); Structuring behaviours of the doctor like Changing of topics ("...] in conversations changing the subject all the time, like yes we are getting back once more to [...], then all of the sudden uh, yes, back, we are going back to that problem." [woman, BE]); Flexibility ('Because it can be very systematic can't it, it's like filling in an application form for something.' [man. UK]); and Time issues ('In the end she did not have time to explain more about it.' [woman, BE]).

A participant gender effect was limited to comments that showed women were more likely to comment positively on doctors' approachability ( $53 \%$ vs $44 \%$; OR $=2.64)$, empathy $(79 \%$ vs $72 \%$; OR $=3.06)$ and directness $(69 \%$ vs $43 \%$; $\mathrm{OR}=4.20$ ), despite their general tendency to be more critical (main effect $\mathrm{OR}=0.60$ ); a doctor gender effect showed that participants disapproved more often the loss of neutrality shown by female doctors ( $78 \%$ vs $54 \%$; OR $=0.27$ - 'I felt that was very dangerous. Simply because at that moment, that was towards the end of the interview, she mixed her personal opinion and her professional opinion. [man, NL]).

Responses to doctors' use of facilitations is also noteworthy. The male participants expressed only positive comments on female doctor behaviours (100\% - 'She said: "I am going to ask you a question a bit awkward, if you like to respond." [...] Maybe this was a form of female solidarity.' [man, IT]), but were critical when associated with male doctors (53\% negative - 'he did interrupt that he didn't let her finish and so on. [man, NL]). Conversely, in the female focus groups, the discussions on this topic were equally distributed over male and female doctors (63\% and $69 \%$ of positive comments respectively).

\section{Discussion}

The present study examined whether communication of male and female doctors is valued differently by men and women. Adopting a mixedmethod approach - specifically the quantitative analysis of qualitative data - made it possible to explore potential gender effects from different points of view.

Overall, there were few differences between male and female focus groups when discussing the quality of male and female doctor communication. The doctor's gender and the participant's gender had no effect on the individual quality ratings of doctors' communication ability, and there were few main effects of participant gender or doctor 
292 Maria Angela Mazzi et al.

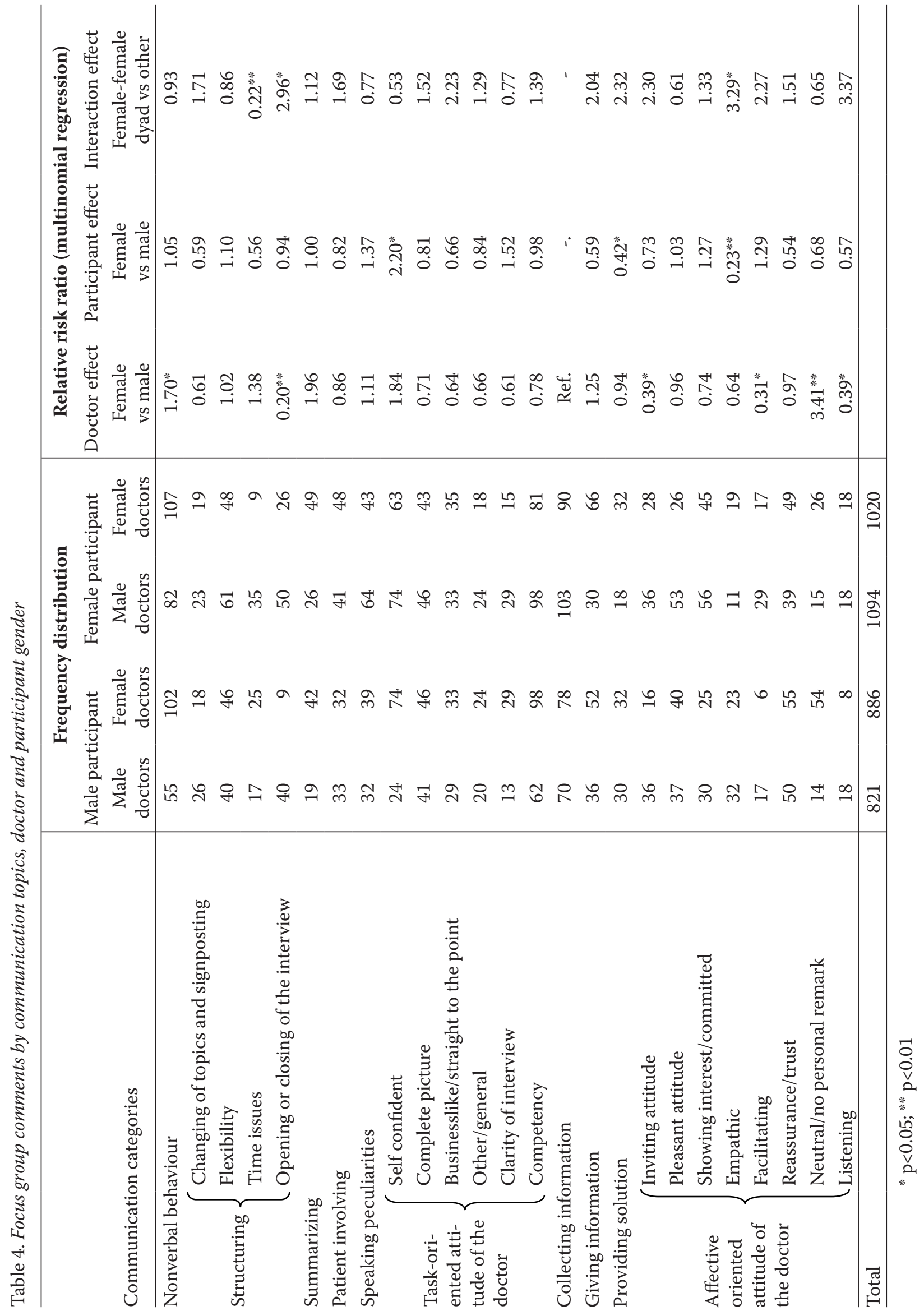

equinoxonlıne 


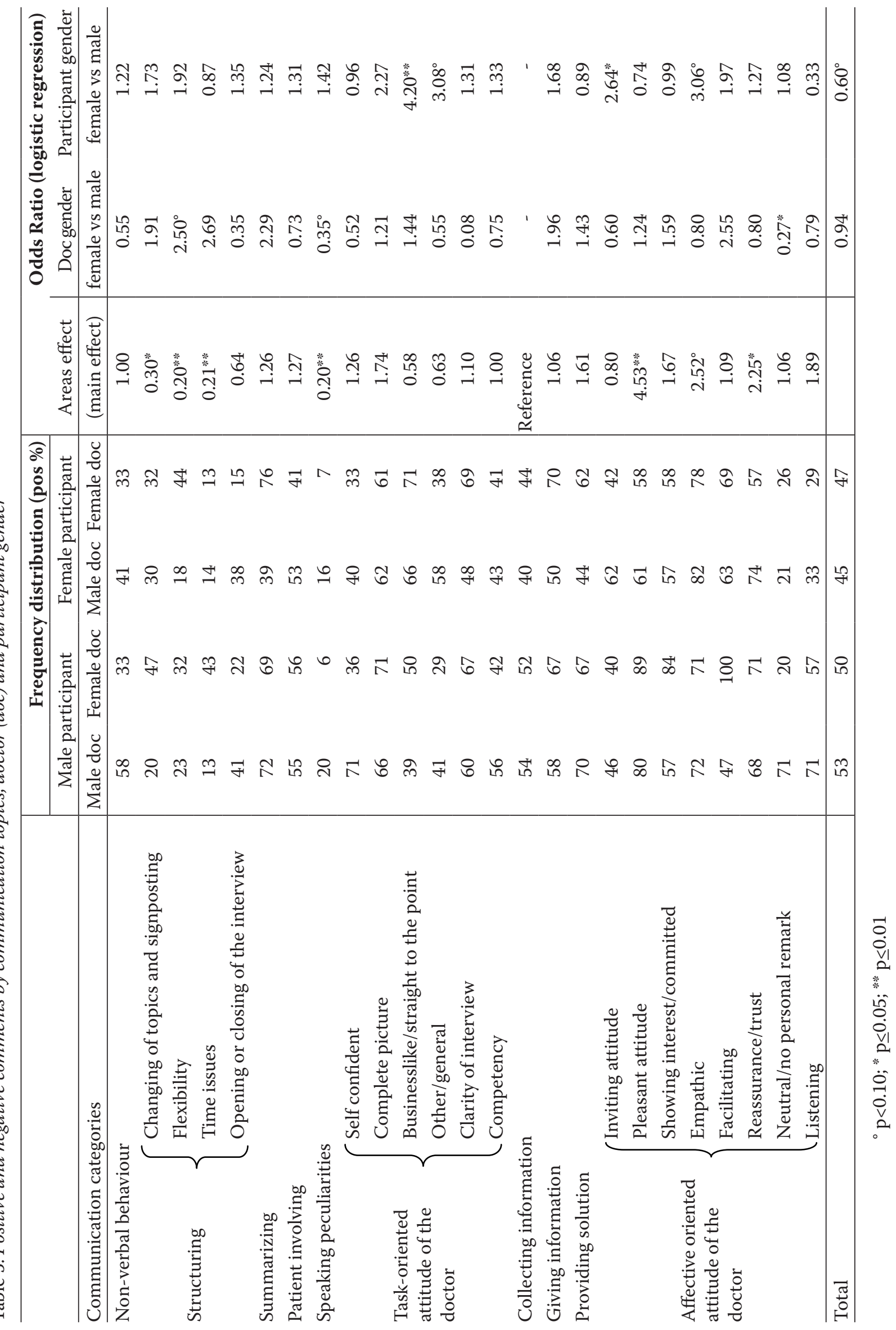


gender on the chosen discussion topics and expressed likes and dislikes. Female participants did, however, tend to be slightly more critical; the only exception is represented by comments on doctors' inviting/straightforward attitude, where women showed a higher appreciation compared to male counterparts. The only significant doctor gender difference that we found was that female doctors were more criticized than male doctors when they were overtly neutral or impersonal. For all other types of communication we did not find any significant difference in the positive or negative appreciation within the four gender dyads. This is remarkable, firstly because of the study design, having separate focus groups for male and female participants, and secondly because of the kind of medical consultation, namely gynaecological problems with psychosocial elements. These create a situation which is most likely to provoke gender-specific reactions in participants. At first sight this lack of clear and substantial gender differences seems surprising. There is convincing evidence that female and male doctors act differently towards patients. Female doctors have longer consultations (Roter et al. 1991; van Dulmen and Bensing 2000), are more patient-centred (Bertakis and Azari 2012), show more partnership and empathy (Roter et al. 2002) and have a stronger psychosocial orientation (Roter and Hall 2004). These are all types of communication which are highly appreciated by most patients (Swenson et al. 2004). However, a recent meta-analysis of studies reporting patients' satisfaction with male and female doctors also found a statistically significant - but very small and barely clinically relevant - gender difference in patient satisfaction (Hall et al. 2011). This might mean that for female doctors, 'female behaviour' - such as empathy, positive non-verbal behaviour and showing support and partnership - is expected. Therefore it is taken for granted and not seen as part of their professional quality. But for male doctors, being empathic and emotionally oriented is seen as a bonus that fosters their professional skills (Schmid Mast et al. 2011).

Again, the women were more critical than the men. It is striking that the women talked in quite critical terms about one particular female doctor who did not live up to the expectations women have for a female doctor. The male participants, meanwhile, tended to be more condoning about the male doctor who evidently had problems talking about sensitive issues, perhaps because from their own experience, they could easily imagine how difficult it is for a man to talk about sensitive female issues. Anyway, it is possible that these expectations have been reinforced by the particularly sensitive female condition presented in the two scenarios. This is suggested by the literature indicating that both male and female patients prefer to see physicians of the same gender, particularly for consultations that involve examination of the genitalia or sexually related topics (Yanikkerem et al. 2009). Unfortunately the OSCE communicative station did not include consultations based on typical sensitive male problems, but it would be interesting to repeat this study with such material.

One particular strength of the study is that the participants watched the same set of videos for each scenario, meaning that the participants all had the same stimuli to react to. Another strength is that the study design (separate focus groups for male and female participants) and choice of medical problem (sensitive gynaecological complaints) maximizes, in theory, the chance of finding gender differences. However, for male participants it will have been harder to identify with the female problems discussed and therefore the results for male participants cannot be generalized to responses to sensitive issues at large. Nevertheless, perhaps because we invited the men to put themselves in the shoes of their sisters or girlfriends, the discussions in the male groups were as lively and open as those in the female groups.

Should gender issues become part of communication training programs? Our findings suggest that for lay persons, gender-related issues in doctor-patient communication are of low priority for both men and women. This is particularly true for highly appreciated behaviours by doctors, which convey empathy, support, understanding and pleasantness, or conversely for highly criticized inadequate behaviours, such as completing a checklist instead of engaging in a real conversation. A warm, empathic, personal approach is valued by all participants and 
appears to transcend patient and doctor gender differences and even the bias of prior role expectations, at least with regard to doctor-patient dyads sharing a European cultural background, as in our study. A clinical approach tailored to the individual, including taking gender into account, thus remains the fulcrum of communication courses.

\section{Appendix: The GULiVer framework}

\begin{tabular}{|c|c|c|}
\hline \multirow{6}{*}{$\begin{array}{l}\text { Non-verbal communication (all } \\
\text { behaviours a GP expresses in non-verbal } \\
\text { form) }\end{array}$} & \multirow{6}{*}{ Non-verbal behaviour } & Facial expression \\
\hline & & Eye contact \\
\hline & & Touch \\
\hline & & Others \\
\hline & & Reading and Writing \\
\hline & & Laughing \\
\hline \multirow{11}{*}{$\begin{array}{l}\text { Process-oriented expressions } \\
\text { (all comments regarding the manner in } \\
\text { which a doctor manages the conversation) }\end{array}$} & \multirow{4}{*}{ Structuring } & Changing of topics and signposting \\
\hline & & Flexibility \\
\hline & & Time issues \\
\hline & & Opening or closing of the interview \\
\hline & Summarizing & Summarizing \\
\hline & \multirow{3}{*}{ Patient-involving } & Sharing plans/ideas \\
\hline & & Asking permission \\
\hline & & Verifying \\
\hline & \multirow{3}{*}{ Speaking peculiarities } & Repetition \\
\hline & & Fillers \\
\hline & & Comprehensibility \\
\hline \multirow{11}{*}{$\begin{array}{l}\text { Task-oriented/problem-focused expres- } \\
\text { sions (all expressions that concern the } \\
\text { instrumental tasks of an interview) }\end{array}$} & \multirow{6}{*}{ Attitude of the doctor } & Self-confident \\
\hline & & Complete picture \\
\hline & & Businesslike / Straight to the point \\
\hline & & Other attitudes \\
\hline & & Clarity of interview \\
\hline & & Competency \\
\hline & \multirow{2}{*}{$\begin{array}{l}\text { Collecting information (ex. } \\
\text { Asking questions) }\end{array}$} & Medical \\
\hline & & Psychosocial \\
\hline & \multirow{2}{*}{ Giving information } & Medical \\
\hline & & Psychosocial \\
\hline & Providing solution & Providing solutions \\
\hline \multirow{8}{*}{$\begin{array}{l}\text { Affective/emotional expressions (all } \\
\text { behaviours focused on affective/emotional } \\
\text { components of an interview) }\end{array}$} & \multirow{8}{*}{ Attitude of the doctor } & Inviting attitude \\
\hline & & Pleasant attitude \\
\hline & & $\begin{array}{l}\text { Showing interest in patient / } \\
\text { commitment }\end{array}$ \\
\hline & & Empathic \\
\hline & & Facilitating \\
\hline & & Reassurance / trust \\
\hline & & Neutral / no personal remark \\
\hline & & Listening \\
\hline \multirow{3}{*}{$\begin{array}{l}\text { General (all statements that concern the } \\
\text { doctor personal characteristics) }\end{array}$} & \multirow{3}{*}{$\begin{array}{l}\text { Socio demographic } \\
\text { characteristics }\end{array}$} & Doctor's gender \\
\hline & & \begin{tabular}{|l|} 
Doctor's age \\
\end{tabular} \\
\hline & & Doctor's ethnicity \\
\hline
\end{tabular}




\section{References}

Arber, J., McKinlay, J., Adams, A., Marceau, L., Link, C. and O'Donnell, A.(2006) Patient characteristics and inequalities in doctors' diagnostic and management strategies relating to CHD: A video-simulation experiment. Social Science and Medicine 62 (1): 103-115. http://dx.doi.org/10.10 16/j.socscimed.2005.05.028

Banerjee, A. and Sanyal, D. (2012) Dynamics of doctor-patient relationship: A cross-sectional study on concordance, trust, and patient enablement. Journal of Family \& Community Medicine 19 (1): 12-19. http://dx.doi.org/10.4103/2230-82 29.94006

Bensing, J. M., van den Brink-Muinen, A. and de Bakker, D. H. (1993) Gender differences in practice style: A Dutch study of general practitioners. Medical Care 31 (3): 219-229. http://dx.doi.org/ 10.1097/00005650-199303000-00004

Bernard, H. R. and Ray, G. W. (2010) Analyzing Qualitative Data: Systematic Approach. Thousand Oaks, CA: Sage.

Bertakis, K. D. and Azari, R. (2012) Patient-centered care: The influence of patient and resident physician gender and gender concordance in primary care. Journal of Women's Health 21 (3): 326-333. http://dx.doi.org/10.1089/jwh.2011.2903

Bertakis, K. D., Franks, P. and Epstein, R. M. (2009) Patient-centered communication in primary care: Physician and patient gender and gender concordance. Journal of Women's Health 18 (4): 539-545. http://dx.doi.org/10.1089/jwh.2008.0969

Betts, P., Wilmot, A. and Taylor, T. (2008) Developing survey questions on sexual identity: Exploratory focus groups. Data Collection Methodology - Social Surveys Census and Social Methodology. London: Office for National Statistics. Retrieved from: http://www.ons.gov.uk/ons/guide-method/measuring-equality/equality/sexual-identity-project/ sexual-identity-focus-group-report.pdf

Blanch-Hartigan, D., Hall, J. A., Roter, D. L. and Frankel, R. M. (2010) Gender bias in patients' perceptions of patient-centered behaviors. Patient Education and Counseling 80 (3):315-320. http:// dx.doi.org/10.1016/j.pec.2010.06.014

Brink-Muinen, A., van Dulmen, S., Messerli-Rohrbach, V. and Bensing, J. (2002) Do gender-dyads have different communication patterns? A comparative study in Western-European general practices. Patient Education and Counseling 48 (3): 253-264. http://dx.doi.org/10.1016/S0738-39 91(02)00178-7
Christen, R. N., Alder, J. and Bitzer, J. (2008) Gender differences in physicians' communicative skills and their influence on patient satisfaction in gynaecological outpatient consultations. Social Science and Medicine 66 (7): 1474-1483. http:// dx.doi.org/10.1016/j.socscimed.2007.12.011

Dielissen, P. W., Bottema B. J., Verdonk, P. and LagroJanssen, T. L. (2009) Incorporating and evaluating an integrated gender-specific medicine curriculum: A survey study in Dutch GP training. BMC Medical Education 9: 58. http://dx.doi.org/10. 1186/1472-6920-9-58, URL: http://www.biomedcentral.com/1472-6920/9/58

Dielissen, P., Bottema, B. J., Verdonk, P. and LagroJanssen, T. (2011) Attention to gender in communication skills assessment instruments in medical education: A review. Medical Education 45 (3): 239-248. http://dx.doi.org/10.1111/j.13652923.2010.03876.x

Dielissen, P., Verdonk, P., Bottema, B., Kramer, A. and Lagro-Janssen, T. (2012) Expert consensus on gender criteria for assessment in medical communication education. Patient Education and Counseling 88 (2): 189-195. http://dx.doi.org/10.1016/j. pec.2012.01.013

Hall, J. A., Blanch-Hartigan, D. and Roter, D. L. (2011) Patients' satisfaction with male versus female physicians: A meta-analysis. Medical Care 49 (7): 611-617. http://dx.doi.org/10.1097/MLR.0b013 e318213c03f

Hall, J. A., Irish, J. T., Roter, D. L., Ehrlich, C. M. and Miller, L. H. (1994) Satisfaction, gender, and communication in medical visits. Medical Care 32 (12): 1216-1223. http://dx.doi.org/10.1097/00005 650-199412000-00005

Hall, J. A. and Roter, D. L. (1995) Patient gender and communication with physicians: Results of a community-based study. Women's Health 1 (1): 77-95.

Hall, J. A. and Roter, D. L. (2002) Do patients talk differently to male and female physicians? A metaanalytic review. Patient Education and Counseling 48 (3): 217-224. http://dx.doi.org/10.1097/MLR. 0b013e318213c03f

Hsieh, H. F. and Shannon, S. E. (2005) Three approaches to qualitative content analysis. Qualitative Health Research 15: 1277-1288. http:// dx.doi.org/10.1177/1049732305276687

Humphris, G. M. and Kaney, S. (2001) The Liverpool brief assessment system for communication skills in the making of doctors. Advances in Health Sciences Education: Theory and Practice 6 (1): 69-80. http://dx.doi.org/10.1023/A:1009879220949 
Jefferson, L., Bloor, K., Birks, Y., Hewitt, C. and Bland, M. (2013) Effect of physicians' gender on communication and consultation length: A systematic review and meta-analysis. Journal of Health Service Research \& Policy 18 (4): 242-248. http://dx. doi.org/10.1177/1355819613486465

Kerssens, J. J., Bensing, J. M. and Andela, M. G. (1997) Patient preference for genders of health professionals. Social Science \& Medicine 44 (10): 1531-1540. http://dx.doi.org/10.1016/S0277-9536(96)00272-9

Lagro-Janssen, T. (2010) Gender and sex: Issues in medical education. GMS Zeitschrift für Medizinische Ausbildung 27 (2): 48-53. http://dx.doi.org/ $10.3205 /$ zma000664.

Mazzi, M. A., Rimondini, M., Deveugele, M., Zimmermann, C., Moretti, F., van Vliet, L., Deledda, G., Fletcher, I. and Bensing, J. (2015) What do people appreciate in physicians' communication? An international study with focus groups using videotaped medical consultations. Health Expectation 18 (5): 1215-1226. http://dx.doi.org/10.1111/ hex.12097

Moretti, F., Fletcher, I., Mazzi, M. A., DeVeugele, M., Rimondini, M., Geurts, C., Zimmermann, C. and Bensing, J. (2012) GULiVer - travelling into the heart of good doctor-patient communication from a patient perspective: Study protocol of an international multicentre study. European Journal of Public Health 22(4): 464-469. http://dx.doi.org/ 10.1093/eurpub/ckr071

Moretti, F., van Vliet, L., Bensing, J., Deledda, G., Mazzi, M., Rimondini, M., Zimmermann, C. and Fletcher, I. (2011) A standardized approach to qualitative content analysis of focus group discussions from different countries. Patient Education and Counseling 82 (3): 420-428. http://dx.doi.org/ 10.1016/j.pec.2011.01.005

Morgan, D. L. (1996) Focus Groups. Annual Review of Sociology 22 (1): 129-152. http://dx.doi.org/10. 1146/annurev.soc.22.1.129

Pluye, P. and Nha Hong, Q. (2014) Combining the power of stories and the power of numbers: Mixed methods research and mixed studies reviews. Annual Review of Public Health 35: 29-45. http:// dx.doi.org/10.1146/annurev-publhealth-0320 13-182440

Risberg, G., Johansson, E. E. and Hamberg, K. (2011) 'Important... but of low status': Male education leaders' views on gender in medicine. Medical Education 45 (6): 613-624. http://dx.doi.org/10.11 11/j.1365-2923.2010.03920.x

Risberg, G., Johansson, E. E., Westman, G. H. and Hamberg, K. (2003) Gender in medicine - an issue for women only? A survey of physician teachers' gender attitudes. International Journal for Equity in Health 2 (1): 10. http://dx.doi. org/10.1186/1475-9276-2-10 URL: http://www. equityhealthj.com/content/2/1/10

Roter, D. L. and Hall, J. A. (2004) Physician gender and patient-centered communication: A critical review of empirical research. Annual Review of Public Health 25: 497-519. http://dx.doi.org/10. 1146/annurev.publhealth.25.101802.123134

Roter, D. L., Hall, J. A. and Aoki, Y. (2002) Physician gender effects in medical communication: A metaanalytic review. Journal of the American Medical Association 288 (6): 756-764. http://dx.doi.org/ 10.1001/jama.288.6.756

Roter, D. L., Lipkin, M. and Korsgaard, A. (1991) Sex differences in patients' and physicians' communication during primary care medical visits. Medical Care 29 (11): 1083-1093. http://dx.doi.org/10.10 97/00005650-199111000-00002

Sandhu, H., Adams, A., Singleton, L., Clark-Carter, D. and Kidd, J. (2009) The impact of gender dyads on doctor-patient communication: A systematic review. Patient Education and Counseling 76 (3): 348-355. http://dx.doi.org/10.1016/j.pec.2009. 07.010

Schieber, A. C., Delpierre, C., Lepage, B., Afrite, A., Pascal, J., Cases, C., Lombrail, P., Lang, T. and Kelly-Irving M. (2014) Do gender differences affect the doctor-patient interaction during consultations in general practice? Results from the INTERMEDE study. Family Practice 31 (6): 706713. http://dx.doi.org/10.1093/fampra/cmu057

Schmid Mast, M., Hall, J. A., Cronauer, C. K. and Cousin, G. (2011) Perceived dominance in physicians: are female physicians under scrutiny? PatientEducation and Counseling 83 (2): 174-179. http://dx.doi.org/10.1016/j.pec.2010.06.030

Schmid Mast, M., Hall, J. A., Klöckner, C. and Choi, E. (2008) Physician gender affects how physician nonverbal behavior is related to patient satisfaction. Medical Care 46 (12): 1212-1218. http://dx. doi.org/10.1097/MLR.0b013e31817e1877

Stata Statistical Software (2011) Release 11.2. College Station, TX: StataCorp LP.

Stewart, D. W. and Shamdasasi, P. N. (2014) Focus Groups: Theory and Practice. Thousand Oaks, CA: Sage.

Swenson, S. L., Buell, S., Zettler, P., White, M., Ruston, D. C. and Lo, B. (2004) Patient-centered communication: Do patients really prefer it? Journal of General Internal Medicine 19 (11): 1069-1079. http://dx.doi.org/10.1111/j.1525-1497.2004.30 384.x 
Thornton, R. L., Powe, N. R., Roter, D. and Cooper, L. A. (2011) Patient-physician social concordance, medical visit communication and patients' perceptions of health care quality. Patient Education and Counseling 85 (2): 201-208. http://dx.doi.org/ 10.1016/j.pec.2011.07.015

van Dulmen, A. M. and Bensing, J. M. (2000) Gender differences in gynaecologist communication. Women Health 30 (3): 49-61. http://dx.doi.org/10. 1300/J013v30n03_04

West, C. (1993) Reconceptualizing gender in physician-patient relationships. Social Science and Medicine 36 (1):57-66. http://dx.doi.org/10.1016/ 0277-9536(93)90305-N

Wolosin, R. J. and Gesell, S. B. (2006) Physician gender and primary care patient satisfaction: No evidence of 'feminization'. Quality Management in Health Care 15 (2): 96-103. http://dx.doi.org/ 10.1097/00019514-200604000-00004

Yanikkerem, E., Ozdemir, M., Bingol, H., Tatar, A. and Karadeniz, G. (2009) Women's attitudes and expectations regarding gynaecological examination. Midwifery 25 (5): 500-508. http://dx.doi. org/10.1016/j.midw.2007.08.006

Maria Angela Mazzi is Statistician at the University of Verona. Her research interests include the statistical approach to doctor-patient communication in medicine and psychiatry (validation of measurement instruments, sequence analysis, multilevel analysis, mixed-method approach) and experimental studies to evaluate psychosocial interventions (RCT). Address for correspondence: Department of Neurological, Biomedical and Movement Sciences, Section of Clinical Psychology, Policlinico G.B. Rossi, Piazzale L.A. Scuro 10, 37134 Verona, Italy. E-mail: mariangela. mazzi@univr.it

Michela Rimondini is Assistant Professor in Clinical Psychology at the University of Verona. Her research interests include the assessment of patient-provider interactions in medicine, the design and evaluation of training courses in patient-centred interviewing, and the qualitative and quantitative assessment of patients' views on communication in medicine. Address for correspondence: Department of Neurological, Biomedical and Movement Sciences, Section of Clinical Psychology, Policlinico G.B. Rossi, Piazzale L.A. Scuro 10, 37134 Verona, Italy. E-mail: michela. rimondini@univr.it
Myriam Deveugele is Professor in Communication in Health Care at the University of Ghent. She is coordinator of a research unit focusing on topics such as quality of communication in the medical encounter, end-of-life communication and intercultural communication issues in medicine. Address for correspondence: Department of General Practice and Primary Health Care, Ghent University, UZ-1K3, De Pintelaan 185, B9000 Ghent. Belgium. E-mail: myriam.deveugele@ugent.be

Christa Zimmermann is Professor of Clinical Psychology at the University of Verona. Her current research interest is in patient-health-provider communication, particularly regarding patients' cue and concerns indicating emotional distress and health-provider responses, and the informative and emotional needs of breast cancer patients and psychiatric patients. Address for correspondence: Department of Neurological, Biomedical and Movement Sciences, Section of Clinical Psychology, Policlinico G.B. Rossi, Piazzale L.A. Scuro 10, 37134 Verona, Italy. E-mail: christa.zimmermann@ univr.it

Giuseppe Deledda is Clinical Psychologist and Head of the Psychological Service at the Ospedale Sacro Cuore Don Calabria in Negrar (Verona). His research interests include the emotional and informative needs of oncological patients and the evaluation of their effect on psychotherapeutic group interventions for oncology patients on diet, physical activity and coping. Address for correspondence: Ospedale Sacro Cuore Don Calabria, Department of Oncology, Psycho Oncology, via Don Sempreboni n 5, Negrar, 37024 Verona, Italy. E-mail: giuseppe.deledda@ sacrocuore.it

Jozien Bensing is Full Professor of Health Psychology at Utrecht University and Honorary Research Fellow on Communication and Health Psychology at NIVEL. Her current research topics include: placebo effects, therapy adherence and communication in healthcare, with particular focus on innovative ways of assessing patient-provider interaction from the patient's point of view. Address for correspondence: NIVEL, Netherlands Institute for Health Services Research, P.O. Box 1568, 3500 BN Utrecht, Netherlands. E-mail: j.bensing@nivel.nl 